\title{
A GATA E O GATO SEM E COM BOTAS: OS CONTOS DE BASILE E DE PERRAULT PELO VIÉS DA INTER- TEXTUALIDADE
}

\author{
Adriana Aparecida de Jesus Reis \\ Graduanda em Letras - Italiano pela Universidade Estadual Paulista (UNESP) \\ adrianareis.ibilce@gmail.com \\ Maria Celeste Tommasello Ramos \\ Livre-Docente em Literatura Italiana pela Universidade Estadual Paulista (UNESP) \\ mct.ramos@unesp.br
}

\section{RESUMO}

Propomos um estudo comparativo entre a narrativa maravilhosa, conhecida como "Cagliuso", presente na obra Pentamerone, do italiano Giambattista Basile (15661632), e "Mestre gato ou o gato de botas", do francês Charles Perrault (1628-1703), que, segundo Coelho (1991), foi inspirada na narrativa italiana de Basile, embora não existam comprovações históricas do contato do escritor francês com os textos do escritor italiano. Com base nas considerações de estudiosos como Darnton (1986), Mendes (2000) e Samoyault (2008), entre outros, verificamos os pontos em comum e as divergências presentes nesse material teórico a fim de compreender se há embasamento suficiente para se afirmar que o conto de Perrault seja uma releitura intertextual do de Basile.

Palavras-chave: Giambattista Basile; Charles Perrault; Cagliuso; Gato de botas; intertextualidade.

\section{RIASSUNTO}

Studio comparato tra la fiaba "Cagliuso", presente nell'opera Pentamerone, dell'italiano Giambattista Basile (15661632) e la fiaba "Il gatto maestro o il gatto con gli stivali", del francese Charles Perrault (1628-1703), che, secondo Coelho (1991), è stata ispirata dalla narrativa italiana di Basile, però non ci sono prove storiche della conoscenza da parte dello scrittore francese dei testi dello scrittore italiano. Sulla base delle considerazioni di Darnton (1986), Mendes (2000) e Samoyault (2008), tra altri studiosi, troviamo punti comuni e divergenze per capire se vi sono proprio motivi per affermare che il racconto di Perrault sarebbe una lettura intertestuale di quello di Basile.

Parole-chiavi: Giambattista Basile; Charles Perrault; Cagliuso; II gatto con gli stivali; intertestualità. 
O italiano Giambattista Basile (1566-1632) foi um dos primeiros escritores a registrar literariamente narrativas maravilhosas, em sua obra prima Lo cunto de li cunti (O conto dos contos), publicada pela primeira vez, postumamente, entre $1634-1636$, em dialeto napolitano, pela irmã do autor, Adriana Basile, famosa cantora de ópera da Itália seiscentista. Por apresentar uma estrutura narrativa análoga à do Decamerone, isto é, a de dez histórias por dia, contadas durante dez dias, de Boccaccio, Benedetto Croce - que, aliás, traduziu a obra composta por cinquenta contos maravilhosos para o italiano standard, em 1925 -, numa referência às cincos jornadas presentes na divisão interna da obra de Basile, atribuiu-Ihe também o título de Pentamerone ossia la fiaba delle fiabe (Pentamerão ou a fábula das fábulas). Perceba-se que o substantivo italiano "fiaba" pode tanto ser traduzido como fábula, quanto como conto maravilhoso ou conto popular, visto que aglutina em si todos esses significados.

O trabalho de Croce foi responsável por dar maior visibilidade à obra de Basile, na península itálica. A publicação original, vazada em dialeto napolitano, da porção meridional da Itália, dificultou muito e quase inviabilizou sua divulgação no restante da península e, por consequência, a obra de Basile não atingiu grande notoriedade no campo da Literatura, quando comparado a outros autores europeus, como Perrault ou os irmãos Grimm.

Basile desempenhou papel político durante sua vida adulta, o que o levou a realizar viagens pelo interior não somente da Campânia, mas também por toda a península itálica, e proporcionou-lhe contato com a cultura popular, ou seja, com as histórias narradas oralmente pelo povo simples. Tal contato Ihe rendeu o conhecimento dos contos populares, relacionados ao modo "maravilhoso", ou seja, narrativas curtas que tinham como enredo elementos mágicos, maldições, encantamentos, transformações, metamorfoses 
etc. Assim, ao longo dos anos, ele escreveu 49 contos maravilhosos emoldurados por um outro conto, que também envolvia o elemento mágico e narrava a história de Zoza.

Na história, ela era uma bela moça que, por ter recebido a maldição de uma velha senhora, havia sido obrigada a procurar o local onde jazia um príncipe adormecido por encanto, tendo-Ihe sido necessário chorar uma ânfora de lágrimas para acordá-lo. Quando estava prestes a completar a ânfora, Zoza adormeceu e uma escrava moura, que a observava ao realizar a tarefa que libertaria o príncipe do encanto, colocou-se no lugar dela e completou a ânfora. Desperto do encanto, o príncipe tomou a escrava como sua salvadora e se casou com ela. Assim que se recuperou do grande cansaço e acordou, Zoza se deu conta de ter sido enganada junto com o príncipe e, por meio de sua própria magia, infundiu na escrava tornada princesa o desejo ardente de ouvir histórias contadas oralmente. A nova princesa convenceu o príncipe a chamar dez velhas contadoras de histórias que tinham apelidos bizarros (característica do grotesco barroco) e vieram então: Zeza (cujo apelido era "aleijada"), Antonella (a "babosa"), Cecca (a "torta"), Ciulla (a "beiçuda"), Meneca (a "queixuda"), Paola (a "vesga"), Tolla (a "nariguda"), Ciommetella (a "tinhosa"), Popa (a "corcunda") e lacova (a "merdosa"), que passaram a contar um conto maravilhoso cada uma por dia, durante cinco jornadas - daí o nome da obra que os reúne ser Pentamerone, que significa "cinco jornadas".

Ao final da quinta e última jornada, depois de ouvirem quarenta e nove contos maravilhosos, Zoza, por meio de magia, substitui a última velha narradora e conta sua própria história como última narração. O príncipe fica sabendo do engano que foi levado a cometer, condena à morte a escrava moura e se casa com Zoza. Assim o enredo do Pentamerone se encerra, condensando dentro de si quarenta e nove contos maravilhosos 
emoldurados pelo que inicia as narrativas e as encerra (ao todo são cinquenta contos, com o conto moldura).

Embora Basile não seja mundialmente conhecido, vários de seus contos do Pentamerone inspiraram clássicos infantis, graças ao trabalho dos filólogos Grimm. Certos contos clássicos podem ter tido sua matriz no Pentamerone, como: "Cinderela" ("La gatta cenerentola"); "Rapunzel" ("Petrosinella"); "O gato de botas" ("Cagliuso"); "Branca de Neve" ("La Schiavottella"); “A bela adormecida" ("Sole, Luna e Talia") e "João e Maria" (“Ninnilo e Nennela").

Os irmãos Grimm, segundo Lombardi (2015), além de estimularem a tradução integral do Pentamerone para o alemão, em 1846, pelas mãos de Liebreth, escreveram um prefácio para a obra traduzida, o que comprova terem tido contato com a obra italiana, provavelmente por meio do amigo ítalo-alemão Clemens Brentano.

No entanto, da relação como fonte de contos de Perrault (1628-1703), e sua obra Contos da Mamãe Gansa (Contes de ma mère l'Oye) não se tem uma comprovação tão forte como aquela citada acima, em relação aos irmãos alemães, no entanto, a estudiosa brasileira Nelly Novaes Coelho (1991) afirma que

Sua [de Basile] grande imaginação produziu narrações tão fabulosas, e seu domínio linguístico tornou-se de tal interesse, que foram traduzidas em nove idiomas e grande parte delas estão na origem dos contos de Perrault. De seu "Cagliuso" saiu O Gato de Botas; de "Sole, Luna e Talia" saiu A Bela Adormecida, de "Zezolla", A Gata Borralheira... (COELHO, 1991, p. 58, grifo nosso).

Entre os contos mencionados por Coelho, está "Cagliuso", do qual saiu "O Gato de Botas", do escritor francês, segundo a afirmação acima, mas não há nenhuma comprovação histórica que Perrault tenha lido o conto de Basile. Por esse motivo, enfocamos, no 
presente estudo, o diálogo intertextual entre o conto "Cagliuso", quarto entretenimento da segunda jornada, e "Mestre gato ou o gato de botas", de Perrault, a fim de verificar em que medida podemos afirmar existir uma espécie de releitura feita por Perrault do conto-fonte de Basile.

Ao analisarmos o suposto texto-fonte de Basile e o texto produzido por Perrault, a primeira divergência encontrada diz respeito ao título, pois a variante italiana é chamada "Cagliuso", o que conduz a atenção para o dono da gata. Diferentemente, a variante francesa é nomeada de "Mestre gato ou o gato de botas"; portanto, chama a atenção para o felino, para sua inteligência e astúcia, ao qualificá-lo "mestre". O mesmo título da variante francesa, devido à presença da conjunção coordenada alternativa "ou", apresenta outra possibilidade de qualificar, utilizando-se da construção gramatical "preposição mais substantivo" ("de botas"). Tal construção, embora não apresente um adjetivo, tem a mesma função dessa classe morfológica, já que restringe ou modifica o substantivo "gato". Desse modo, podemos sugerir que o acessório (botas) será de tamanha utilidade ao gato, que o levará a ser mestre e, portanto, astucioso, o que nos leva a supor, inicialmente, que este objeto terá função mágica, já que estamos no terreno do maravilhoso.

Já no conto "Cagliuso", o título é o nome do dono da gata, cujo pai mendigo realizou a partilha de seus únicos bens entre seus dois filhos, momentos antes de morrer: o mais velho, de nome Oraziello e, o caçula, de nome Cagliuso, dando ao primeiro uma peneira e ao caçula uma gata.

Na narrativa francesa, o início dá contas ao leitor da divisão realizada entre filhos de um moleiro, que "deixou como únicos bens, para os três filhos que tinha, seu moinho, seu burro, e seu gato. A partilha foi feita logo, sem que fossem chamados nem notário, nem procurador" (PERRAULT, 1994, p. 55). Assim, o mais moço também recebe um gato 
de herança, porém, do sexo masculino, configurando um ponto convergente e ao mesmo tempo divergente entre as duas narrativas: o animal é o mesmo, mas é macho.

Em relação à herança dos irmãos mais velhos, já notamos uma significativa divergência: na variante francesa, o primogênito recebe um moinho e o segundo um burro. Com isso, podemos perceber que, embora os objetos partilhados sejam diferentes, com exceção do animal felino para o filho mais moço, todos são de valor não muito alto. São dois filhos no texto italiano e três no francês.

Além de nomes italianos para os personagens, no texto maravilhoso de Basile, existem referências geográficas relacionadas à Nápoles, cidade ao sul da península itálica já citada na primeira linha do início da narrativa: “Era uma vez, na cidade de Nápoles, um velho mendigo, desgraçado, azarado, sem a sombra de um quatrim que andava nu como um piolho"' (BASILE, 2014, p. 1, grifo nosso). Além dessa referência, encontramos outra indicando ruas de Melito, a Pedra do Peixe e a Floresta de Astroni. A primeira, no século XVII, era conhecida como uma zona de parada de mendigos por levar a um local chamado Fascenario, para onde os pedintes eram conduzidos. A segunda é uma das fontes históricas de Nápoles, onde, antigamente, se concentrava o comércio relacionado à pesca, realizado por muitos negociantes, que a distribuíam aos vendedores de peixe e, por fim, a terceira, por estar situada em uma zona vulcânica, é também chamada, atualmente, de Cratera de Astroni, a qual ainda é um dos poucos lugares onde há uma grande variedade de plantas. Além disso, antigamente, essa floresta, por conter uma grande quantidade de animais selvagens, era um local de caça para os nobres. Todas essas referências demonstram que Basile, além de recolher os contos da oralidade, lhes adicionou um sabor napolitano. 
Após a partilha dos patrimônios, os filhos caçulas passam a se lamentar, pois os gatos inicialmente não lhes pareciam trazer benefícios, se comparados aos presentes de seus irmãos mais velhos. Diante disso, os gatos têm a mesma atitude: repreendem seus donos, alegam que podem ser um presente valiosíssimo se agirem. No entanto, notamos uma divergência quanto aos seus discursos, pois a gata de Basile não pede nada, mas o gato, na variante francesa, além de repreender seu dono, pede-lhe dois objetos, um saco e um par de botas, como podemos observar em: “'Não se aflija, patrão, é só me dar um saco, e mandar fazer um par de botas para andar na macega, e verá que não foi tão mal aquinhoado como pensa'" (PERRAULT, 1994, p. 55, grifo nosso). Mas é inegável que os dois felinos falam, atestando a presença do elemento maravilhoso em ambas as narrativas, pois, de acordo com Todorov (2010, p. 59 e 60), em A introdução à Literatura fantástica, o gênero maravilhoso é o gênero literário em que a presença no sobrenatural não promove hesitação interna (personagens) e externamente (leitores) à obra, em oposição ao gênero fantástico.

Cagliuso ouve e passa a confiar em sua gata, acariciando seu dorso, entretanto, não temos informação a respeito do que ela possa ter feito para obter esse carinho e, consequentemente, sua confiança, pois o narrador não nos esclarece: "Cagliuso, não se sabe ao certo por quê, agradeceu a Sua Senhoria Gata, fez-lhe duas ou três carícias sobre o dorso e passou a confiar nela calorosamente ${ }^{\mathrm{ii} \prime \prime}$ (BASILE, 2014, p. 2, grifo nosso). Feito o pedido, o gato de botas francês começa a fazer várias acrobacias para apanhar ratos e camundongos, pendurando-se pelos pés ou se escondendo na farinha para fingir de morto. Ao ver essas habilidades, seu dono começa a confiar nas palavras de seu gato, pois “[...] não duvidou que pudesse ser socorrido por ele em seu infortúnio" (PERRAULT, 1994, p. 56). 
Em seguida, a gata, na variante italiana, começa a agir: toda manhã, ela dirige-se à Pedra do Peixe, para roubar peixes de pescadores, e à Floresta de Astroni, para roubar aves de caçadores; depois os leva de presente ao rei da região em nome de seu dono Cagliuso com a finalidade de despertar na autoridade local o interesse de conhecer Cagliuso. O gato da versão francesa age de forma semelhante, visto que, após receber de seu patrão um saco e um par de botas, objetos mágicos que tanto desejava, apanha coelhos e aves (perdizes), e leva-os ao rei, como enviados por seu patrão.

Embora tenham as mesmas ações, os gatos referem-se a seus donos de formas distintas, porque a gata diz o verdadeiro nome de seu patrão, ou seja, ele afirma que são presentes enviados por Cagliuso. Já o gato inventa a alcunha "marquês de Carabás" para se referir ao seu dono que, até então, não tinha nome na narrativa, mas o recebe, acompanhado de função social na nobreza - marquês. Título irônico, a nosso ver, se pensarmos em sua importância no contexto em que Perrault viveu, isto é, o da corte francesa dos séculos XVII e XVIII. Nesse período em especial, segundo o historiador Costa (2014, p. 75), tal título passou a dividir o mesmo patamar com conde, visconde e barão, títulos anteriormente inferiores, ficando abaixo dos príncipes de sangue e duques, portanto, houve uma desvalorização, já que não carregava um status social elevado, contudo, na narrativa de Perrault, o gato trama ações para justamente sugerir ao Rei o contrário, isto é, que seu dono, chamado marquês de Carabás, era um nobre rico. Embora seja irônica e/ou contraditória em relação ao contexto extratextual, tal escolha, a nosso ver, foi muito bem acertada, pois ela já antecipa a pretensão do gato, visto que, dentro da hierarquia monárquica, segundo Nogueira (2002), o cargo de marquês era geralmente ocupado por homens de alta confiança do rei, a quem era atribuída a proteção de distritos, chamados de marcas, daí o título marquês, cujo significado é governador de marcas, em regiões 
fronteiriças ou mal pacificadas. Desse modo, por meio da alcunha dada pelo gato, já podemos vislumbrar as intenções do felino em tornar seu dono um homem de confiança do rei daquela região.

Após receberem várias caçadas de presentes em nome de Cagliuso, na versão italiana, e em nome do Marquês de Carabás, na variante francesa, as autoridades reais decidem recompensar todas as cortesias, contudo, a forma de recompensa é divergente: na variante italiana, o rei deseja conhecer Cagliuso, portanto, o objetivo da gata logo é atingido. Na variante francesa, pelo contrário, o rei dá ao gato uma gorjeta como recompensa, portanto, a intenção do gato inicialmente não é alcançada. Diante da falta de sucesso imediato, o gato traça mais um astucioso plano: sabendo que o rei iria passear na beira do rio com sua filha, "a mais bela princesa do mundo" (PERRAULT, 1994, p. 58), o gato pediu ao marquês de Carabás que fosse se banhar. Assim, no momento mais oportuno, o gato se pôs a gritar pedindo socorro ao rei para seu dono que estava se afogando no rio. O rei, depois de reconhecer o gato, que the tinha tantas vezes trazido caças, ordenou que seus servos o socorressem.

Continuando a mentira, o gato alega roubo das roupas de seu senhor, e ele recebe um traje do rei, como aconteceu no texto-fonte italiano: o rei desejava conhecer aquele que Ihe mandava caças pela gata, mas ela lhe diz que seu senhor foi roubado na noite anterior, até suas roupas se foram, e o rei manda-lhe novas e belas roupas, outra convergência entre o texto de Basile e o de Perrault.

Estando bem trajados, Cagliuso, no conto italiano, e o marquês de Carabás, no conto francês, têm uma oportunidade de conhecer, de fato, o rei durante um banquete. Para comprovar que seus senhores são ricos, tanto a gata de Basile quanto o gato de Perrault usam de uma estratégia baseada na argumentação. A de Basile leva consigo servos 
do rei para visitar as propriedades de seu senhor, mas lhes diz que prefere ir à frente para garantir alojamentos pela longa estrada que deveriam percorrer. Igualmente age o gato no conto francês, pois enquanto o marquês participava do passeio na carruagem com o rei e a bela princesa, ele ia na frente para ameaçar os camponeses no campo dizendo: “Boa gente que está ceifando, se não disserem ao rei que o campo que está ceifando pertence ao senhor marquês de Carabás, vão virar picadinho que nem carne de patê" (PERRAULT, 1994, p. 61, grifo nosso). Neste discurso do gato, podemos perceber que, para ameaçar os camponeses, ele os compara à carne de patê, mais precisamente, ao modo como ela é talhada, isto é, feito picadinho. Desse modo, para analisar tal elemento em destaque, trazemos à luz os estudos da pesquisadora Karin Volobuef (2011), que afirma:

por exemplo, na "Bela adormecida no bosque", de Perrault (2004), a protagonista é criticada pelo príncipe (cem anos mais novo do que ela) por usar roupas do tempo de sua vó, e a ogra (mãe do príncipe) ordena ao cozinheiro que prepare e Ihe sirva as crianças (seus próprios netos) com molho roberto. $O$ que vemos em Perrault é uma contextualização social e cultural, que remete a valores ou costumes da aristocracia francesa: a valorização da moda, o refinamento da culinária e o distanciamento nas relações familiares (VOLOBUEF, 2011, p. 57-58, grifo nosso).

Fundamentando-nos nessa afirmação, podemos perceber que a estudiosa salienta, na análise de outro conto de Perrault, a presença de costumes que remetem à aristocracia francesa, como o refinamento da culinária. Assim, podemos dizer que o elemento "carne de patê" no conto "Mestre gato ou o gato de botas", também de Perrault, está ligado ao refinamento da culinária igualmente, marca de seu estilo literário, como destaca Darnton: 
Perrault, mestre do gênero, realmente recolheu seu material da tradição oral do povo (sua principal fonte, provavelmente, era a babá de seu fiIho). Mas ele retocou tudo, para atender ao gosto dos sofisticados frequentadores dos salões, précieuses e cortesãos aos quais ele endereçou a primeira versão publicada de Mamãe Ganso, seu Contes de ma mere l'oye, de 1697 (DARNTON, 1986, p. 24).

Essa ameaça do gato, faz referência a práticas históricas (canibalismo e violência) e oferece-nos pista para a prática de roubos na França do século XVIII, decorrentes das dificuldades financeiras e da baixa produtividade agrícola das colheitas, a qual, como se depreende por meio da afirmação de Darnton (1996, p. 44), era muito comum naquele contexto.

Porém, apesar de tomar dianteira para ludibriar, a gata, no conto italiano, usandose da persuasão argumentativa, inventa que uma trupe de bandidos estava saqueando aquela região e que, por esta razão, ela os aconselhava a dizer que todos os animais e propriedades pertenciam ao senhor Cagliuso: “Olá, fiquem atentos que um monte de bandidos deseja saquear tudo aquilo que se encontra nestes pastos! Por esse motivo, se vocês desejam evitar roubos e salvar seus animais e bens, digam que eles pertencem ao senhor Cagliuso, e ninguém terá coragem de tocar em sequer um pelo iii” (BASILE, 2014, p. 3). Com essas palavras, os camponeses, preocupados em serem roubados, para se salvaguardar, confirmaram para os emissários do rei o que a astuciosa gata Ihes recomendou, fato que conquistou a confiança do rei, o qual, após os emissários Ihe narrarem "os mares e montes de riquezas do senhor Cagliuso ${ }^{\text {iv” }}$ (BASILE, 2014, p. 4), não teve mais dúvida de que o Cagliuso era mesmo milionário, e deu a mão de sua filha e um grande dote ao rapaz. Após as festividades matrimoniais, Cagliuso e a princesa foram para a Lombardia, onde, com o conselho da gata, comprou terras e tornou-se barão. 
Assim ocorre também com o dono da gata da releitura francesa: depois de interrogar os lavradores, e acreditar que um belo castelo real era do Marquês, o rei ofereceIhe a mão da princesa. Assim como Cagliuso, também o Marquês de Carabás ascende socialmente ao enganar o rei, graças à esperteza de seu gato.

Uma divergência final comparece na releitura: ao final, a relação entre a gata e seu dono é rompida, pela ingratidão do dono, no texto-fonte, pois ela decidiu fingir-se de morta, com a finalidade de testar seu dono, uma vez que ele lhe havia prometido que "quando [a gata] morresse, talvez em cem anos, faria com que [ela] fosse embalsamada e colocada em uma gaiola de ouro em seu leito, para tê-la sempre diante de seus olhos ${ }^{\mathrm{v} \prime}$ (BASILE, 2014, p. 4). No entanto, ele se livra dela, mas ela se mostra viva, e vai embora, abandonando o dono, dizendo ter obtido o seguinte aprendizado: “Que Deus nos proteja do rico empobrecido e do mendigo enriquecido ${ }^{\text {vi” }}$ (BASILE, 2014, p. 5), proverbio napolitano que encerra o conto "Cagliuso". Na releitura, nada afeta a relação amigável do gato de botas e seu marquês, pois eles usufruem juntos de uma situação socialmente prestigiada até o desfecho eufórico da narrativa.

Dessa expressão proverbial napolitana, reproduzida pela personagem felina ao final da narrativa de Basile, é possível retirarmos um aprendizado, pois o provérbio é uma expressão que remonta à sabedoria e à experiência popular. Este caráter popular é confirmado, a nosso ver, pelo dispositivo estético da rima entre os adjetivos "empobrecido/enriquecido" (português), "impoverito/arricchito" (italiano) e "'mpoveruto/resagliuto" (napolitano), pois, conforme Darnton (1996, p. 31), a rima, ao lado da repetição, era um mecanismo mnemônico utilizado pelos contadores de histórias, narradores camponeses que, apesar de adaptarem o cenário de seus relatos a seu próprio contexto, mantinham 
outros detalhes em detrimento de dispositivos linguísticos que garantiam sua fixação na memória, e por conseguinte, a difusão do história oral sem perder algumas informações.

Além disso, o que reforça o aspecto moralista do provérbio, na narrativa de Basile, é o fato de o narrador observador colocar, na voz da personagem gata, o ensinamento moral, isto é, uma espécie de aprendizado.

Não obstante as narrativas de Basile e de Perrault tenham finais distintos, já que somente o gato de botas francês não tem seus laços rompidos com o marquês de Carabás, convergentemente, no que tange ao aspecto estrutural, a variante francesa também é encerrada por expressões, de cunho moralizante, já que no próprio texto, de autoria francesa, essas expressões são intituladas de "Moral". Contudo, tal moral é escrita em forma de versos, detalhe que, a nosso olhar, oferece à narrativa um toque ainda mais poético se compararmos às rimas.

Na releitura de Perrault, destacamos o seguinte trecho que também traz uma moral: "Se um filho de um moleiro, com presteza, / Cativa o coração de uma princesa, / E atrai o seu olhar enamorado, / É que para inspirar tal ternura / Aparência, juventude e formosura / São recursos a ser considerados" (PERRAULT, 1994, p. 70, grifo nosso), no qual são valorizadas a aparência, a juventude e a formosura do rapaz, realçados pelas mentiras e ações persuasivas e ameaçadoras do seu gato. Destaca valores apreciados na época de Perrault, devido ao luxo dos salões literários franceses frequentados pelo escritor, conforme Mendes (2000, p. 125).

Acreditamos que também ironizam a falta de esperteza da personagem feminina, aqui representada pela figura da princesa, já que ela foi enganada pelo gato e pelo marquês. Para reforçar nossa interpretação acerca da personagem feminina, trazemos o comentário feito pelo narrador, no momento em que a princesa é oferecida ao marquês 
pelo rei: "O rei, encantado com as boas qualidades do senhor marquês de Carabás, assim como sua filha, que estava louca por ele, e vendo os muitos bens que possuía, disse-lhe, após ter bebido uns cinco ou seis copos: - Dependerá somente do senhor marquês, tornar-se meu genro" (PERRAULT, 1994, p. 69, grifo nosso). Essa marca de intrusão destacada, com tom depreciativo, parece-nos zombar e/ou nos revelar o quanto a personagem feminina era levada pela aparência, o que nos mostra o quanto a mulher, na sociedade em que Perrault viveu, era vista como alienada, o que vai ao encontro da opinião de Mendes (2000), quando a pesquisadora indaga se escritor francês pode ser mesmo considerado um feminista:

[...] Perrault frequentava os salões literários das 'preciosas' e chegou mesmo a defender publicamente as mulheres contra os ataques de Boileau, escrevendo o poema Apologia das mulheres. Pode-se imaginar que o poeta tenha até mesmo tentado ser um 'feminista'. Mas nas entrelinhas do seu texto, o que transparece são os preconceitos de uma sociedade machista, que via a mulher como ridículo (MENDES, 2000, p. 126, grifos nossos).

Para embasar tal conclusão a que chegou, Mendes (2000) analisa alguns exemplos, retirados da narrativa cotejada em nosso estudo e outras, para nos mostrar a ironia depreciativa em relação às mulheres, já que, segundo ela, nas narrativas de Perrault, quando “[...] os homens (príncipes) se deixavam impressionar pela aparência das mulheres (princesas ou camponesas), [...] não surge nem comentário irônico a esse respeito" (MENDES, 2000, p. 126). Por este motivo, a pesquisadora propõe o termo feminilidade e não feminismo para se referir às personagens femininas dos contos de autoria de Perrault. Por feminilidade, podemos entender a condição feminina expressa na caracterização das personagens, ou seja, nos contos do escritor francês, a mulher pode "[...] ser for- 
te e poderosa como as fadas, ou frágil e dependente como as princesas" (MENDES, 2000, p. 126).

Dessa maneira, uma vez que a mulher é comumente representada de forma depreciativa, em outras palavras, ridicularizada nos contos do escritor francês, a nosso ver, o atributo da esperteza foi deslocado da gata, de Basile, para o gato, personagem masculino na narrativa de Perrault.

Além disso, ao mesmo tempo que preservou o nível narrativo da história entre o viés parafrásico e o estilístico do diálogo intertextual que travou, com muitas convergências demonstradas com o texto-fonte de Basile, o que comprova, em nosso ponto de vista, ser a narrativa de Perrault uma releitura, o escritor francês, ao recontá-la, adaptou alguns elementos à moda francesa, a qual é evidenciada pelo refinamento da culinária e pela valorização da moda, que também está presente no uso das botas pelo gato francês. Mas Basile também trouxe referências a elementos napolitanos. Talvez a intertextualidade se estenda também à obra do escritor italiano Straparola, assunto para outro artigo.

Enfim, ao compararmos as duas narrativas, percebemos que, na releitura, Perrault conservou muitos acontecimentos de seu texto-fonte italiano: a história de um jovem pobre e injustiçado que foi beneficiado pela engenhosidade de seu animal felino, que reverteu a situação inicial de miséria, transformando-a em riqueza. Existem muitas convergências na releitura que, a nosso ver, constituem o que o Jolles (1976, p. 188) designa de fundo, pois é o que se manteve resistente no recontar da história. Este fundo invariável, além de permitir que o leitor reconheça os possíveis diálogos intertextuais, preserva a memória da Literatura, que se renova e se faz presente mesmo após centenas de anos (SAMOYAULT, 2008). Reler o texto de Basile por parte de Perrault confirma que a Literatura é viva. 


\section{Referências}

BASILE, Giambattista. Cagliuso. Lo cunto de li cunti: Il giornata. Napoli: Isola dei ragazzi, 2014, p. 01-04. [Versão italiana de Domenico Basile e Grazia Zanotti Cavazzoni em formato e-book].

Cagliuso. Lo cunto de li cunti. Milano: Garzanti, 2013, p. 324-333.

COELHO, Nelly Novaes. Panorama histórico da Literatura Infanto-Juvenil: das origens indo-europeias ao Brasil contemporâneo. São Paulo: Ática, 1991.

COSTA, Antonio Luiz M. C. Títulos de Nobreza e Hierarquias: um guia sobre as graduações sociais na história. São Paulo: Draco, 2014.

DARNTON, Robert. Histórias que os camponeses contam: O significado de Mamãe Ganso. In: . O grande massacre de gatos e outros episódios da história cultural francesa. Tradução Sonia Coutinho. Rio de Janeiro: Edições Graal, 1986. p. 21-101. (Biblioteca de História, 13).

I PROVERBI NAPOLETANI. In: CORDO di Napoli. Disponível em:

$<$ http://www.corpodinapoli.it/ospitalita/napoletanita/proverbi.html> Acesso em: 10 jul. 2018.

JOLLES, Andrè. O conto. In: Formas simples. Tradução Álvaro Cabral. São Paulo: Cultrix, 1976.

MENDES, Mariza B. T. Em busca dos contos perdidos: o significado das funções femininas nos contos de Perrault. São Paulo: Editora da UNESP; Imprensa Oficial do Estado de São Paulo, 2000.

NOGUEIRA, Carlos Roberto Figueira. Como se organiza a nobreza. Revista Superinteressante, 2002, s/p. Disponível em: https://super.abril.com.br/historia/comose-organiza-a-nobreza/>. Acesso em: 29 jun. 2018.

PERRAULT, Charles. Mestre gato ou o gato de botas. In: Contos da mamãe gansa. Tradução Elisa Tamajusuku, Maria Alves Müller e Maria Stella Dischinger da Cunha. Porto Alegre: Paraula, 1994. p. 53-70.

VOLOBUEF, Karin. Os Irmãos Grimm e as raízes míticas dos contos de fadas. In: ALVAREZ, Roxana Guadalupe Herrera et al. (org.). Dimensões do fantástico, mítico e maravilhoso. São Paulo: Cultura Acadêmica, 2011, p. 47-61. 
SAMOYAULT, Tiphaine. A intertextualidade. Tradução Sandra Nitrini. São Paulo: Aderaldo \& Rothschild, 2008.

TODOROV, Tzvetan. Introdução à Literatura Fantástica. Tradução Maria Clara Correa Castello. 4. ed. São Paulo: Perspectiva, 2010.

Recebido em 30 de maio de 2019.

Aceite em 9 de novembro de 2019.

\footnotetext{
i Tradução nossa de: C'era una volta nella città di Napoli un vecchio così pezzente, disgraziato, scalognato, senza il becco di un quattrino che se ne andava in giro nudo come un pidocchio.

ii Tradução nossa de: Cagliuso, poiché non si sa mai, ringraziò Sua Signoria la Gatta, le fecce due o tre carezze sulla schiena e le si raccomandò caldamente.

iii Tradução nossa de: [...] rispose che non si poteva neanche contare esattamente il gran numero di mobili, palazzi, suppellettili di questo gran riccone, che lui stesso non sapeva quanto possedeva [...].

iv Tradução nossa de: mari e monti della ricchezza del signor Cagliuso.

v Tradução nossa de: quando [la gatta], di lì a cent'anni lei fosse morta, l'avrebbe fatta imbalsamare e mettere in una gabbia d'oro nella sua camera, per averla davanti agli occhi.

${ }^{v i}$ Tradução nossa de: Dio ti guardi dal ricco impoverito e dal vilano arricchito.
} 